\title{
Do Day Traders Rationally Learn About Their Ability?
}

\author{
Brad M. Barber \\ Graduate School of Management \\ University of California, Davis \\ Yi-Tsung Lee \\ Guanghua School of Management \\ Peking University \\ Yu-Jane Liu \\ Guanghua School of Management \\ Peking University \\ Terrance Odean \\ Haas School of Business \\ University of California, Berkeley \\ Ke Zhang \\ Haas School of Business \\ University of California, Berkeley
}

October 2017

We are grateful to the Taiwan Stock Exchange for providing the data used in this study. Barber appreciates the National Science Council of Taiwan for underwriting a visit to Taipei, where Timothy Lin (Yuanta Core Pacific Securities) and Keh Hsiao Lin (Taiwan Securities) organized excellent overviews of their trading operations. We have benefited from the comments of seminar participants at the University of Southern California, the University of Oregon, the University of Utah, the University of Virginia, Santa Clara University, the University of Texas, Texas A\&M, Washington University, Peking University, and HKUST. 


\title{
Do Day Traders Rationally Learn about Their Ability
}

\begin{abstract}
We analyze the performance of and learning by individual investors who engage in day trading in Taiwan from 1992 to 2006 and test the proposition that individual investors rationally speculate as day traders in order to learn whether they possess the superior trading ability. Consistent with models of both rational and biased learning, we document that unprofitable day traders are more likely to quit than profitable traders. Inconsistent with models of rational speculation and learning, we document that the aggregate performance of day traders is negative, that the vast majority of day traders are unprofitable, and many persist despite an extensive experience of losses, .
\end{abstract}


Papers (Mahani and Bernhardt (2007) and Linnainmaa (2010)) develop models in which an individual investor rationally chooses to trade speculatively-knowing that most other individuals lose money through speculation - in order to learn whether or not she has the ability to reliably profit through speculation. In these models, investors do not initially know their own abilities and rationally infer these by observing their trading performance. Gervais and Odean (2001) present a model in which biased learning leads successful investors to become overconfident. In this model, too, investors do not initially know their own abilities and must infer these from performance. However, when they are successful, these investors irrationally attribute success disproportionately to their ability rather than luck, leading investors to overestimate their own abilities and trade too aggressively; even investors with more past failures than successes may become overconfident by overweighting their successes.

We test the predictions of rational Bayesian learning models by analyzing the performance of day traders in Taiwan. We focus on day traders, those who buy and sell the same stock within a day, as these traders are almost surely speculators. Using the complete transaction data for the Taiwan Stock Market over 15 years (1992 to 2006), we find evidence of learning among day traders. The majority of day traders quit relatively quickly (more that $75 \%$ of all day traders quit within two years), and poor performers are more likely to quit. These results are consistent with the models of both rational and biased learning. In this respect, our paper complements the emerging evidence that learning is an important factor in the behavior of individual investors. Using Finnish data, Seru, Shumway, and Stoffman (2010) document investors not only learn about their ability by trading, but also get better with experience. Linnainmaa (2010) calibrates a structural model in which investors rationally learn about their ability through trading using trading records of active individual Finnish investors. Consistent with the prediction of his model, investors are more likely to increase trade size after successful trades and more likely to decrease trade size or quit trading after unsuccessful trades. Furthermore, the size and quitting effects are stronger early in an investor's career, when his or her prior beliefs about ability are more diffuse. Using US broker data, Nicolosi, Peng, and Zhu (2009) show that trade intensity increases following signals of strong 
performance. Analyzing data from the National Stock Exchange in India, De et. al. (2010) document that investors increase trading in response to recent profits and that the sign of profits matters more than their magnitude.

Previous tests of rational learning models of trading have focused primarily on confirming evidence, e.g., do investors increase (decrease) trading in response to successful (unsuccessful) trades? To properly test these models it is, however, equally or more important to also look for disconfirming evidence. While we, too, find clear evidence of learning, we also document behavior that is not consistent with rational Bayesian learning as modeled by Mahani and Bernhard (2007) and Linnainmaa (2010) for two reasons:

First, if the entry (and exit) of new speculators who are testing their trading acumen is stable over time, then the sign of the expected lifetime profits of new speculators is the same as that of aggregate speculator profits. Therefore risk-averse or risk-neutral potential speculators with no special prior knowledge of their abilities should only "trade to learn" if aggregate speculator profits are positive. In fact, using complete data for the Taiwan market, the aggregate performance of day traders net of fees is negative in each of the 15 years that we study. A profit-maximizing risk-averse (or riskneutral) Bayesian investor would not enter a market if her expected lifetime profits were negative.

Second, though performance affects day trader survival, many poor performing traders persist. Each month from 1993-2005, we sort traders based on the number of days they have engaged in day trading as of the end of the previous month and on the past profitability of their intraday trades. To have an accurate measure of day trading experience, we exclude traders who day traded in 1992. Previously unprofitable traders with 50 or more days of past day trading experience have a $95.3 \%$ probability of day trading again in the next 12 months, while previously profitable traders with 50 or more days of past day trading experience have a $96.4 \%$ probability doing so. So, not only do 
experienced day traders with histories of losses persist in day trading, they do so at nearly the same rate day traders who have been profitable.

The rest of this paper is organized as follows. After reviewing related research (section I), we discuss Taiwan market rules, data, and methods (section II). In section III, we present the performance of day traders sorted in aggregate and partitioned by past performance and trading activity. In section IV, we explore the source of profits for profitable day traders. In section $\mathrm{V}$, we explicitly test the learning models. After discussing our results (section VI), we make some concluding remarks (section VII).

\section{Learning by Speculators}

The suggestion that investors learn from experience is neither novel nor controversial. ${ }^{1}$ Learning is a ubiquitous feature of human experience. From a welfare and policy perspective, the question is not whether investors learn, but how well they learn. In this section we develop testable predications that emanate from a rational model of learning and highlight the predictions would discriminate between rational and biased models of learning.

Mahani and Bernhardt (2007) argue that rational Bayesian learning can explain several empirical regularities: cross-sectionally, most speculators lose money; large speculators outperform small speculators; past performance positively effects subsequent trade intensity; most new traders lose money and cease speculation; and performance shows persistence. Similar to Mahani and Bernhardt (2007), Linnainmaa (2010) develops a structural model of rational learning. Using trading data from Finland, he finds investors with poor performance are likely to quit and trading intensity increases following good performance.

\footnotetext{
1 A number of papers document investor learning in various forms including Feng and Seasholes (2005), Seru, Shumway, and Stoffman (2007), Nicolosi, Peng, and Zhu (2009), Chiang, Hirshleifer, Qian, and Shreman (2010), Choi, Laibson, Madrian and Metrick (2010), De, Gondhi, and Pochiraju (2010), and Odean, Strahilesvitz, and Barber (2010).
} 
In Mahani and Bernhardt (2007), novice speculators lose while the experienced profit, but aggregate performance should be positive and represent an upper bound on the return to day trading. To see the logic behind this assertion, consider the following simple, concrete, example. Suppose that 21 new speculators try trading each year. Only one of these has skill; 20 are unskilled. Unskilled speculators trade for one year, lose $\$ 1$, and quit. Skilled speculators trade for 10 years, earn $\$ 1$ each year and quit. Thus aggregate speculator profits each year are $-\$ 10$. Because skilled speculators stay in the market longer, skilled speculators account for a greater fraction of active speculators (i.e., 10/30) than of new speculators (i.e., 1/21). Expected lifetime profits for a new speculator are $(1 / 21) \$ 10+(20 / 21)(-\$ 1)=-\$ 0.476$. Note that aggregate annual profits divided by the number of new speculators each year are equal to expected lifetime profits (i.e., $\$ 10 / 21=-\$ 0.476$ ) and that aggregate annual profits divided by the number of all speculators trading in a year (e.g., $-10 / 30=-\$ 0.333$ ) are of the same sign but lower magnitude than expected lifetime profits. Thus, when aggregate profits are negative, they provide an upper limit to the unconditional expected lifetime profits of a speculator. If traders have rational prior beliefs about the unconditional expected lifetime profits from engaging in speculations, then the aggregate performance of speculators should be positive. This leads to our first null hypothesis:

H1: The aggregate net performance of day traders is positive (non-negative).

The alternative is that the aggregate net performance of day traders is negative. This is consistent with traders holding biased prior beliefs about the unconditional expected lifetime profits from trying day trading.

In the rational learning models, unsuccessful traders quit trading after the accumulation of negative signals outweighs their positive initial prior beliefs about their ability. Gervais and Odean (2001) develop a model in which investors take too much credit for their success and thus, relative to a Bayesian, overweight successes when learning about their ability. In their model, too, successful investors have more ability than unsuccessful ones and investors respond to good performance by trading more aggressively. In contrast to the rational Baysian model, their model can also explain persistent trading by previously unsuccessful traders; these traders put too much weight on successes and too little on failures when updating beliefs about their abilities 
Persistent trading in the face of losses is not consistent with the models of rational learning. However, it is difficult to disentangle whether an unprofitable day trader is persisting because of biased learning or biased priors beliefs. Without a clear and accurate model of quickly traders should learn from losses coupled with estimates of prior beliefs, one cannot say precisely how quickly unsuccessful rational traders should quit. We present evidence of remarkable trading persistence in the face of losses, for example, nearly 3/4ths of day-trading volume is generated by unsuccessful day-traders with at least 10 days of day trading experience. The reader must assess for him or herself whether this perverse persistence is due to biased prior beliefs, biased learning, or both.

The rational learning models predict that unsuccessful speculators will quit while successful speculators are likely to persist. Thus-irrespective of prior beliefs-the rational learning models predict our second null hypothesis:

$\mathrm{H} 2$ : Experienced day traders with previous net losses will not continue to trade.

Under Gervais and Odean's biased learning model, it is possible for unsuccessful traders to become overconfident, and more active traders, if their learning bias is sufficient. Thus continuing to trade by unprofitable day-traders is contrary to the rational learning models but consistent with biased learning.

\section{Data and Methods}

\section{II.A. Day Traders and Speculative Trading}

Empirical tests of the learning models must identify traders who trade speculatively. Investors might reasonably trade to save (or consume), to rebalance their portfolios, or to reduce their tax liability. Thus, an important feature of our empirical strategy is to identify a clean sample of speculators. We do so by focusing on day trading on the Taiwan Stock Exchange. Day trading is the purchase and sale of the same stock by an investors on a day. We argue that these intraday trades are almost certainly speculative. Moreover, day trading is common and prevalent in Taiwan. 
We are not the first to study day trading, though the sample of day traders we study is much larger and the time-series much longer than those in prior studies. ${ }^{2}$ The one exception to this generalization being Barber, Lee, Liu, and Odean (2010) who identify a small subset of day traders (less than $1 \%$ of the day trading population) predictably earn profits. None of these prior studies used the empirical setting to test rational and biased models of learning, the focus of our investigation.

\section{II.B. Taiwan Market Rules}

Before proceeding, it is useful to describe the Taiwan Stock Exchange (TSE). The TSE operates in a consolidated limit order book environment where only limit orders are accepted. During the regular trading session, from 9:00 a.m. to noon during most of our sample period, buy and sell orders can interact to determine the executed price subject to applicable automatching rules. ${ }^{3}$ Minimum tick sizes are set by the TSE and vary depending on the price of the security. Generally, orders are cleared using automatching rules one to two times every 90 seconds throughout the trading day. Orders are executed in strict price and time priority. An order entered into the system at an earlier time must be executed in full before an order at the same price entered at a later time is executed. Although market orders are not permitted, traders can submit aggressive price-limit orders to obtain matching priority. During our study period, there is a daily price limit of $7 \%$ in each direction and a trade-by-trade intraday price limit of two ticks from the previous trade price.

Since our analysis focuses on day trading, an important consideration is transaction costs. The TSE caps commissions at $0.1425 \%$ of the value of a trade. Some brokers offer lower commissions for high-volume traders. Officials at brokerage firms and the TSE indicated to us that the largest commission discount offered is $50 \%$ (i.e., a commission of roughly 7 basis points); these same officials estimated the trade-weighted

\footnotetext{
${ }^{2}$ Harris and Schultz (1998) study SOES bandits at two brokers. Garvy and Murphy $(2002,2005)$ analyze 15 and 1,386 day traders at one US broker. Seasholes and $\mathrm{Wu}(2004)$ analyze the trades of 10 active traders on the Shanghai Stock Exchange. Linnainmaa (2003) analyzes 7,686 Finnish day traders.

${ }^{3}$ Trading also occurred on Saturdays during most of our sample period. Before December 1997, Saturday trading occurred from 9:00-11:00. From January to March, 1998, stocks were traded only on the second and the fourth Saturday in each month. From April 1998 to December 2000, Saturday trading occurred from 9 am to noon. From 2001 on, there has been no trading on Saturday.
} 
commission paid by market participants to be about 10 basis points. We use the 10 basis points when calculating returns net of fees. Taiwan also imposes a transaction tax on stock sales of $0.3 \%$.

\section{II.C. Trades Data and Descriptive Statistics}

We use a unique and remarkably complete dataset, which contains the entire transaction data, underlying order data, and the identity of each trader on the Taiwan Stock Exchange (TSE). With these data, we provide a comprehensive accounting of the profitability of day traders during the period 1992 through 2006.

The trade data include the date and time of the transaction, a stock identifier, order type (buy or sell -- cash or margin), transaction price, number of shares, a broker code, and the identity of the trader. In total, the dataset contains 3.7 billion purchase (or sale) transactions with a value of \$NT 310 trillion (approximately \$10 trillion US). ${ }^{4}$ The trader code allows us to broadly categorize traders as individuals, corporations, dealers, foreign investors, and mutual funds. The majority of investors (by value and number) are individual investors. Corporations include Taiwan corporations and government-owned firms (e.g., in December 2000 the government-owned Post, Banking, and Insurance Services held over \$NT 213 billion in Taiwanese stock). ${ }^{5}$ Dealers include Taiwanese financial institutions such as Fubon Securities, Pacific Securities, and Grand Cathay Securities. Foreign investors are primarily foreign banks, insurance companies, securities firms, and mutual funds. During our sample period, the largest foreign investors are Fidelity Investments, Scudder Kemper, and Schroder Investment Management. Mutual funds are domestic mutual funds, the largest of which is ABNAMRO Asset Management with \$NT 82 billion invested in Taiwanese stocks in December 2000.

\footnotetext{
${ }^{4}$ The mean TWD/USD exchange rate from 1992 to 2006 was 30.54 with a low of 24.65 and a high of 35.01 .

${ }^{5}$ Many corporations are small firms that are majority or wholly owned by an individual. Thus, the corporate category of trader also includes thousands of individual investors who trade under the label of corporation.
} 
We define day trading as the purchase and sale, in any order, of the same stock on the same day by an investor. Specifically, if an investor buys and sells the same stock on the same day, we calculate the number of shares bought $\left(S_{b}\right)$, the number of shares sold $\left(S_{s}\right)$, the average purchase price $\left(P_{b}\right)$, and the average sales price $\left(P_{s}\right)$. The value of day trading is defined as half of the total value of sales and purchases $\left(1 / 2 * P_{b} * \min \left(S_{b}, S_{s}\right)+\right.$ $\left.1 / 2 * P_{s} * \min \left(S_{b}, S_{s}\right)\right)$. Over our sample period, aggregate day trading accounts for more than $19 \%$ of the total dollar value of aggregate trading volume. Most day trading (about $2 / 3^{\text {rds }}$ ) involves the purchase and sale of the same number of shares in a stock over the course of one day (i.e., most day trades yield no net change in ownership at the close of the day).

Virtually all day trading can be traced to individual investors. In the average month, individual investors account for over $99 \%$ of all day traders (and $95 \%$ of day trading volume). Individuals and corporations are free to short sell, though dealers, mutual funds, and foreigners are prohibited from doing so on the TSE. These short sale restrictions might partially explain the tendency for day trading to concentrate among individual investors. In contrast to U.S. markets, dealers are not active providers of liquidity. TSE rules state that dealers are required to "efficiently adjust the demand and supply in the market depending on the market situation, and ensure that the formation of fair price and its sound operation are not harmed," yet dealers face no specific penalties for failing to meet this requirement. Dealer trades emanate from their proprietary trading activity. Based on our discussions with dealers in the TSE, the majority of this proprietary trading is not necessarily intended to provide liquidity. Chae and Wang (2003) also report that TSE dealers are not net providers of liquidity. In the remainder of the paper, we focus on individual investors.

In Figure 1, we plot day trading as a percentage of total trading volume and the number of individuals who day trade by month. While day trading was somewhat less prevalent in the early part of our sample period, the share of volume traced to day trading has been consistently around $20 \%$ of total trading volume from 1995 to 2006. In the average month, almost 140,000 individuals day trade. With an adult population of about 16 million (total population about 22 million), this means just shy of $1 \%$ of the adult 
population day trades in the average month. In terms of both a percentage of total trading volume and numbers of traders, day trading is an equilibrium feature of the Taiwan stock exchange with no apparent trend over the from 1997 through 2006.

\section{II.D. Performance Measurement}

Our primary performance measurement focuses on the intraday profits of all trades made by day traders and on trade-weighted intraday returns. In a subsequent analysis, we also analyze the event time profitability of purchases and sales to ensure the inferences we draw from the analysis of intraday profits are accurate.

We first calculate the intraday returns to day trading. To do so, we identify all trades made by day traders. We calculate the profits on round-trip day trades and other position opening trades that remain open at the close of the trading day. The other trades are either purchases to open a long position or sales that open a short position. The profits for trades that lead to an open position are calculated relative to closing prices on the date of the trade (i.e., mark-to-market at the day's closing price). To calculate the daily return earned by a day trader, we sum the proceeds from stocks sold to close long positions and bought to close short positions (or their mark-to-market equivalent at the close of the trading day) and divide by the cost of initiating the position (i.e., the value of stocks bought or sold short at the time of the purchase or sale). We refer to this return as the gross intraday return from day trading. To calculate the net intraday return to day trading, we assume a 5 basis points (bps) commission on purchases, a 5 bps commission on sales, a 30 bps transaction tax on sales. (See appendix for details.)

It is important to include both round-trip and one-sided trades to measure the performance of day trading. Focusing only on round-trip trades would yield a biased measure of performance if investors sell winners and hold losers (i.e., exhibit the disposition effect). For example, assume some day traders randomly buy and sell (random traders), while others close only winning investments while riding losers (disposition traders). Were we to analyze only the profits of round-trip trades, it is clear that the disposition traders would have better round-trip returns than the random traders merely because they have a rule regarding when to close a position. Since the disposition 
effect is prevalent among Taiwanese investors and among day traders elsewhere, ${ }^{6}$ it is important to include both round-trip and other trades when analyzing performance.

In Figure 2, we present an example of four trades by a day trader. The red lines represent short positions, while the black lines represent long positions. The solid lines are the portion of returns that are included in our day trading profits, while the dashed lines are included in the analysis of long-run returns. It's clear from this graph that, by combining the two analyses, we capture the full experience of a trader.

\section{Rational and Behavioral Learning Models: Confirming Evidence}

We begin by estimating the survival rate of day traders. Our trading data starts in 1992. To reasonably ensure that we are analyzing new day traders, we restrict our analysis to those who begin day trading after 1992. Our data ends in 2006 and thus is right-censored. We consider a trader to have quit day trading if we observe no day trading for 12 consecutive months. As a result of this requirement, we do not analyze day traders who begin day trading in 2006 since we cannot reliably observe whether they have quit.

In Figure 3, we present a five-year Kaplan-Meier survival function. We consider the survival of day traders who have day traded for at least 10 days - and designate the first month when they hit the minimum 10-day threshold as their entry month.

For many of these traders, day trading is a persistent activity. Only $2.5 \%$ drop out within one month, while survival rates at one, two, and three years are $44 \%, 24 \%$ and $15 \%$ respectively.

To test whether magnitude of past profitability affects the decision to quit day trading, we estimate the following Cox proportional hazard rate model, $h(t, x)=h_{0}(t) e^{\{X B\}}$, where $X$ is a matrix of independent variables, $B$ is a vector of

\footnotetext{
${ }^{6}$ Barber, Lee, Liu, and Odean (2007) and Linnainmaa (2005) document, respectively, that individual Taiwanese investors and Finnish day traders exhibit the disposition effect.
} 
coefficient estimates, $h_{0}(t)$ is the baseline hazard rate (i.e., the hazard rate when all covariates are equal to zero), and $h(t, x)$ is the hazard rate conditional on a set of covariates $(x)$ at time $t$. In our application, a trader becomes at risk of quitting once he begins day trading.

Again, we restrict our analysis to day traders who have day traded for a minimum of 10 days. To assess the impact of past performance on quitting, we use net intraday returns. To estimate the impact of past returns on the propensity to quit day trading, we construct a series of 26 dummy variables corresponding to the following ranges in basis points: $(-\infty,-90],(-90,-85], \ldots,(25,30],(30, \infty)$. When estimating the Cox proportional hazard rate model, we set the range $(0,5 \mathrm{bps}]$ as the default category and include the remaining 25 dummy variables as covariates in our estimation. As control variables we include measures of past day trading activity: the log of the number of days with day trading activity, the log of the number of days since a trader's first day trade, and the log of the total volume of day trading. In the event history analysis, all independent variables are updated monthly.

The results of this analysis are presented in Figure 4. The horizontal axis of the figure represents net intraday return categories, while the vertical axis represents the hazard rate relative to the omitted profit category (net intraday return in the interval $(0$, 0.05]). As predicted by the learning models, the net intraday return is negatively related to the hazard rate. More profitable day traders are less likely to quit. ${ }^{7}$

However, the effect is not linear. The propensity to quit is relatively insensitive to differences past net intraday returns in the $-30 \mathrm{bps}$ to $30 \mathrm{bps}$ range. Traders with past net intraday returns in the $(30 \mathrm{bps}$, infinity) range are more likely to quit than those with

\footnotetext{
${ }^{7}$ The relation between profits and the propensity to quit is similar regardless of whether we include control variables. However, the control variables are all reliably related to hazard ratios at the $1 \%$ significance level. Traders with more days of day trading experience are less likely to quit; a one standard deviation increase in the log of number of days of past day trading reduces the base case hazard rate to 0.43. Day traders who have been trading longer are more likely to quit; a one standard deviation in the log of the number of days since a trader's first day trade increases the hazard rate to 1.24. Heavy day traders are more likely to quit; a one standard deviation increase in the log of past day trading volume increases the hazard rate to 1.11 .
} 
returns in the $-30 \mathrm{bps}$ to $30 \mathrm{bps}$ range, though not as likely as traders with more negative returns.

In the domain of negative returns, the propensity to quit is quite sensitive to the magnitudes. For example, consider the impact on hazard rates of moving across four equidistant profit categories: $(0,0,05],(-0.30,-0.25],(-0.60,-0.55]$ and $(-0.90,-0.85]$. The first move, from just profitable to the low range of losses increases the hazard rate six percentage points (from 1.00 to 1.06); the second move, from the low range of losses to mid range losses, increases the hazard rate by an additional 30 percentage points (from 1.06 to 1.36 ), the third move, from the mid range of losses to a high range increases the hazard rate by an additional 36 percentage points (from 1.36 to 1.72).

In summary, these analyses provide strong evidence that traders learn about their own ability by trading. Those who profit are less likely to quit, though the effect is most pronounced for those with steep losses.

\section{III.A. Rational Learning Models: Disconfirming Evidence}

To this point, we find support for the rational and behavioral learning models of investor behavior. Poor performers are more likely to quit day trading.. The confirming evidence indicates learning is an important feature of financial markets. In this section, we argue that rational learning does not explain behavior of the large population of speculative investors for three reasons: aggregate performance is negative, experienced speculators lose money, and unprofitable speculators persist.

\section{A. 1. Aggregate performance is negative}

To evaluate the performance of day traders relative to their opportunity cost of holding the market portfolio, we estimate abnormal returns by regressing the portfolio excess return (portfolio return less risk-free rate) on the excess return on a valueweighted market index. We construct our own market index using market capitalization from the Taiwan Economic Journal (TEJ) and individual stock returns calculated from the TSE data. The intercept of this regression is our measure of abnormal returns. 
In Table 1, we present the gross and net performance of all day traders. Though our performance analysis weights investors by the investments they make, we do not distinguish occasional day traders from active day traders in this preliminary analysis. We analyze the day trades and other trades of these investors in the months in which they day trade.

There are two reasons that including all trades in the month of day trading might positively bias our performance analysis. First, due to the disposition effect, day traders are more likely to close profitable positions. Thus, months in which we observe day trading are more likely to be profitable months. Second, it is possible that good investment performance leads to day trading (i.e., reverse causation). (In subsequent analyses, we identify day traders ex-ante to avoid these issues.) We are not concerned by these biases in this preliminary analysis since we document poor performance in aggregate.

In the second column of Table 1, we present the gross abnormal intraday returns of day traders. On average, day traders lose 7 basis points on their day trading before costs $(t=-10.2)$. In the fourth column we see that trading costs more than triple the losses to 23.9 basis points per day. Moreover, we observe reliably negative gross and net performance in all years but 1992.

In aggregate, day trading is a losing proposition; day trading is an industry that consistently and reliably loses money. From an industrial organization perspective, it is difficult to understand how such an industry survives. For people to knowingly day trade, most must either be overconfident about their prospects of success or derive non-financial utility from the activity and knowingly suffer losses as a result. Finally, the poor aggregate performance of day trading is not consistent with the learning model of Mahani and Bernhardt (2007). In their model, novice speculators lose while the experienced profit, but aggregate performance should be positive and represent the equilibrium return 
to day trading. We discuss this issue in detail and explicitly test rational learning models after presenting results on cross-sectional variation in performance.

\section{A. 2. Experienced Day Traders Continue To Lose Money}

A central feature of the learning model is the observation that bad traders quit. This raises two natural questions. First, do traders with a long history of losses continue to trade? Second, what fraction of day trading can we trace to traders with a history of losses?

Do traders with a long history of losses continue to trade? To investigate the relation between experience, past performance, and continued trading we categorize day traders into groups based upon past day trading experience and whether or not they have been profitable Each month from 1993-2005, we sort traders based on the number of days they have engaged in day trading and on the cumulative profitability of their past intraday trades as of the end of the previous month. To have an accurate measure of day trading experience, we exclude traders who day traded in 1992. We exclude traders with fewer than 10 days of past day trading experience sorting the remaining traders into those with 10 to 49 days, 50 to 99 days, 100 to 199 days, 200 to 399 days, and 400 or more days of day trading experience. We further partition these experience groups into those with positive cumulative past intraday profits and those with negative or zero cumulative past intraday profits. We then measure the propensity for traders in each experience/profitability group to stop day trading for one month or for twelve consecutive months.

Table 2 Panel A reports the rate at which traders stop day trading for at least one month. Not surprisingly, traders with less experience are more likely to stop. For example, $41.98 \%$ of profitable traders and $43.19 \%$ unprofitable traders with 10 to 49 days of experience stop trading for at least one month while only $7.58 \%$ of profitable traders and $9.30 \%$ of unprofitable traders with 400 or more days of experience do so. What is more surprising is that the rates at which traders stop trading is almost the same whether they have been profitable or unprofitable. 
Table 2 Panel B reports the rates at which traders stop day trading for at least twelve consecutive months. Naturally, these rates are lower than those for stopping for a month, but a similar pattern emerges as in Panel A. 5.43\% of profitable traders and $6.55 \%$ of unprofitable traders with 10 to 49 days of experience stop trading for at least twelve months. Of traders who have day traded 400 or more days, profitable traders have a $1.58 \%$ probability of quitting for twelve or more months and unprofitable traders have a $2.05 \%$ probability quitting. Using columns $2-5$ and the last four rows of Panel B one can calculate that all previously unprofitable traders with 50 or more days of past day trading experience have a $95.3 \%$ probability of day trading again in the next 12 months, while previously profitable traders with similar experience have a $96.4 \%$ probability doing so. Traders are sensitive to losses, but not very sensitive.

What fraction of day trading can we trace to traders with a history of losses? To answer this question, each month we sort traders who day trade that month into three groups: occasional day traders - traders with 1 to 9 days of day trading experience; unprofitable day traders - traders with 10 or more days of day trading experience and negative (or zero) life time net intraday profits (prior to the month of sorting); profitable day traders - traders with 10 or more days of day trading experience and positive life time net intraday profits (prior to the month of sorting. In Figure 5 we graph the relative sizes of these three groups from 1995 through 2006 when measured by number of traders (Figure 5a) and trading volume in dollars (Figure 5b). Throughout this twelve-year period the fraction of profitable day traders is consistently about 5\%. The fraction of unprofitable traders grows to over $2 / 3$ rds as more and more occasional day traders are reclassified as profitable or unprofitable. As one would expect, profitable and unprofitable day traders account for proportionately more trading volume that occasional day traders. In aggregate over the sample period, unprofitable traders account for $72 \%$ of trading volume and in the last several years of the sample they consistently account for about $80 \%$ of trading volume. 
Thus, most day traders are unprofitable, most day trading is generated by previously unprofitable traders, and unprofitable day traders with considerable experience persist at day trading at almost the same high rate at profitable experienced day traders. These observations are not consistent with models of rational learning.

\section{A. 3. Event Time Analysis and the Persistence of Performance}

So far we considered only intra-day returns. This is appropriate given our focus on day trading. However, not all positions initiated by day traders are closed the day they are opened. Do day traders earn profits on positions that they hold beyond the close of trading? We address this question with an event time analysis of returns subsequent to purchases and sales.

Each day we sort traders on profitability and experience over the last 365 calendar days (366 for leap years). Profitable (unprofitable) is cumulative intraday net profits over the previous year that are positive (negative or zero). Experience bins are based on number of days of day trading during the previous 365 days with: Low experience (0-5), Exp. 2 (6-10), Exp 3 (11-20), Exp 4 (21-40), Exp 5 (41-80), Hi Exp ( > 80). We aggregate all purchases by day traders in each group by stock and day where the day of the transaction is event day 1 . We then calculate the mean market-adjusted abnormal return on event day $\tau\left(\mathrm{MA}_{\tau}\right)$ (weighted by the value of stocks bought) using purchase prices and closing prices to calculate event day 1 market adjusted returns and ignoring trading costs. There is a similar calculation for the sales of each group. Finally, we calculate the cumulative (market-adjusted) abnormal return on stocks bought less the cumulative (market-adjusted) abnormal return on stocks sold as:

$$
C A R_{T}=\sum_{\tau=1}^{T}\left(M A_{\tau}^{\text {buy }}-M A_{\tau}^{\text {sell }}\right) .
$$

The results for a 10 trading day event horizon are displayed in Figure 7. The most striking results in the graph are: 1) irrespective of experience, traders with past profits outperform those with past losses and 2) for traders with positive past profits, cumulative abnormal returns increase with experience, and 3) profitable traders with more than 40 
days of day trading experience in the last year earn more than enough to cover 40 basis points of round trip transaction costs. Most of this profit is earned on the day of the transaction.

We look at the persistence of profitability from another angle by calculating, as in Table 1, gross and net abnormal intraday returns. We partition day traders daily using the same criteria as for Figure 6. Results are reported in Table 3. 1) Irrespective of experience, traders with past profits outperform those with past losses, 2) for traders with positive past profits, cumulative abnormal returns increase with experience, and 3) profitable traders with more than 40 days of day trading experience in the last year earn more than enough to cover their transaction costs.

These results confirm that an extensive history of profitability is a strong predictor of future profitable. However, very few traders are predictably profitable. In the last column of Table 3 , we see that only $9.81 \%(3.20 \%+6.61 \%)$ of day trading volume is generated by predictably profitable day traders. From column 8 , we can calculate that these predictably profitable traders constitute less than $3 \%$ of all day traders on an average day.

\section{Discussion}

Our data are remarkably well suited for testing models of rational learning such as Mahani and Bernhard's. Mahani and Bernhard write that their "prototypical novice speculator is the Japanese hairdresser Kiyoshi Wakino" who day trades between giving haircuts (p. 1317). We observe the day trading of hundreds of thousands of investors over a seventeen-year period. And while our day traders are Taiwanese and certainly not all hairdressers, it is probable that-like Kiyoshi Wakino - many of our novice day traders pursue trading in addition to, if not during, a regular job. Despite the size and appropriateness of our data, our results simply do not support the rational learning models. In Mahani and Bernhard's model, day trading is, in aggregate, profitable because skilled day traders are able to take advantage of the insensitivity of liquidity traders to price and the willingness of competitive market-makers to forego a profit. In Taiwan, day 
traders, in aggregate, lose money. Therefore it is not rational for a risk-averse investor with no special claim to superior ability to undertake day trading in hopes of discovering that he is amongst the chosen few. Furthermore, it is not rational for day traders who have incurred persistent losses to continue day trading for the purpose of learning about their ability.

So why do investors take up day trading and why do so many persist in the face of losses? We consider three broadly defined answers to this question.

First, it could be the case that day traders do not have standard risk-averse preferences; they may be risk-seeking or attracted to investments with highly skewed investments, such as lotteries, that have negative expected returns but a small probability of a large payoff as suggested by Kumar (2009). However, the day trading profits that we document are similar in magnitude to, and far less prevalent than, the losses. Unlike lottery winners, day traders must succeed on repeated gambles in order to achieve overall success. Such repeated gambles do not tend to generate highly skewed distributions. Furthermore, daily day trading returns have a negative mean, and yet lower variance and less right-hand skewness than the average Taiwanese stocks. Define the annual day trading return as the sum of the returns earned on each day of day trading. For traders with a minimum of ten days of day trading, the skewness of the annual return is -0.22 (i.e., modestly negatively skewed). In contrast, when we calculate the skewness of annual returns across individual stocks listed on the TSE from 1981 to 2009, the coefficient of skewness is positive in all but one year and averages 2.36. Thus, a risk or lottery seeker could better maximize his utility, with far less effort, by simply buying and holding a single volatile stock.

Second, day traders may be overconfident in their prior beliefs about their abilities and biased in the way they learn. Several papers (e.g., Odean (1998, 1999), Barber and Odean $(2000,2001))$ argue that overconfidence causes investors to trade more than is in their own best interest. Overconfident day traders may simply be bearing losses that they did not anticipate. While novice day traders undoubtedly realize that other day 
traders lose money, stories of successful day traders may circulate in non-representative proportions, thus giving the impression that success is more frequent than it is. Once investors undertake day trading, their prior overconfidence may be reinforced through biased learning as in Gervais and Odean (2001). Furthermore, heavy day traders, who earn gross profits but net losses, may not fully consider trading costs when assessing their own ability.

Third, day traders may trade for non-financial motivations including entertainment, a taste for gambling, and the desire to impress others (see, e.g. Grinblatt and Keloharju (2009)). Some investors may enjoy the process of day trading so much that they are willing to persist in the face of regular losses. Some investors may be attracted to the casino like qualities of day trading with its frequent bets, wins, and losses. ${ }^{8}$ Some investors may choose to day trade in hopes of impressing others. ${ }^{9}$

We are unable to explicitly test whether day traders are motivated by overconfidence rather than the desire for entertainment, gambling, or to impress others. Nor is there reason to believe that overconfidence and non-financial motivations are mutually exclusive. Quite to the contrary, entertainment, gambling, and the desire to impress others are all likely to be more attractive reasons to trade if one is overconfident about one's likelihood of success.

In Mahani and Bernhard's model, "all speculators are made worse off if some speculators are slightly overconfident" (p. 1315). Our results are consistent with this prediction. If heavy day traders persist in trading due to overconfidence, then that overconfidence is detracting from their own welfare and that of other speculators. The welfare of the heavy traders themselves is diminished because, on average, they earn net losses; the welfare of other speculators is diminished because, on average, heavy traders

\footnotetext{
${ }^{8}$ Kumar (2009) shows a correlation between the propensity to gamble and the types of investment decisions U.S. investors make. Barber, Lee, Liu, and Odean (2008) document that the introduction of a National Lottery in Taiwan coincided with a significant drop in trading volume on the Taiwan Stock Exchange. Grinblatt and Keloharju (2009) document that investors prone to sensation seeking trade more frequently.

${ }^{9}$ Several papers argue that investment decisions are influenced by social concerns, for example, Barber, Heath, Odean (2003), Statman (2004), and Hong and Kacperczyk (2009).
} 
earn gross profits thereby reducing the average returns of other investors. The beneficiaries of this overconfidence are brokerage firms - through commissions - and the government - through the transaction tax.

\section{Conclusion}

We test predictions of models of learning by rational traders and find clear evidence that the decision to continue or increase day trading is influenced by previous day trading returns. Nevertheless, rational models of learning do not explain all or even most day trading. The most experienced day traders lose money and nearly $3 / 4$ ths of day trading can be traced to traders with a history of losses. Persistent trading in the face of losses is inconsistent with models of rational learning. So, too, is the decision to try day trading when ex-ante expected lifetime profits are negative. For prospective day traders, "trading to learn" is no more rational or profitable than playing roulette to learn. 


\section{References}

Barber, Brad M., Chip Heath, and Terrance Odean, 2003, Good Rationales Sell: ReasonBased Choice Among Group and Individual Investors in the Stock Market, Management Science, 49, 1636-1652.

Barber, Brad M., Yi-Tsung Lee, Yu-Jane Liu, and Terrance Odean, 2007, Is the Aggregate Investor Reluctant to Realize Losses? Evidence from Taiwan, European Financial Management, 2007, Vol. 13, 423-447.

Barber, Brad M., Yi-Tsung Lee, Yu-Jane Liu, and Terrance Odean, 2008, Just How Much Do Individual Investors Lose by Trading?, Review of Financial Studies, forthcoming.

Barber, Brad M., Yi-Tsung Lee, Yu-Jane Liu, and Terrance Odean, 2010, Do Some Individual Investors have Skill: Evidence from Day Trading, working paper.

Barber, Brad M., and Terrance Odean, 2000, Trading Is Hazardous to Your Wealth: The Common Stock Investment Performance of Individual Investors, Journal of Finance, 2000, Vol. 55, No. 2, p.773-806.

Barber, Brad M., and Terrance Odean, 2001, Boys will be Boys: Gender, Overconfidence, and Common Stock Investment, Quarterly Journal of Economics, 116, 261-292.

Chae, Joon, and Albert Wang, 2003, Who Makes Markets? Do Dealers Provide or Take Liquidity? working paper \#4434-03, MIT, Cambridge, MA.

De, Sankar, Gondhi, Naveen R. and Pochiraju, Bhimasankaram, 2010, Does Sign Matter More than Size? An Investigation into the Source of Investor Overconfidence. Available at SSRN: http://ssrn.com/abstract=1657926

Garvey, Ryan, and Anthony Murphy, 2002, How Profitable Day Traders Trade: An Examination of Trading Profits, working paper, University College Dublin, Dublin, Ireland.

Gervais, Simon, and Terrance Odean, 2001, Learning to be Overconfident, Review of Financial Studies, 14, 1-27.

Garvey, Ryan and Anthony Murphy, 2005, The Profitability of Active Stock Traders, Journal of Applied Finance, 93-100.

Grinblatt, Mark, and Matti Keloharju, 2000, The Investment Behavior and Performance of Various Investor Types: A Study of Finland's Unique Data Set, Journal of Financial Economics, 55, 43-67. 
Grinblatt, Mark, and Matti Keloharju, 2001, What makes investors trade?, Journal of Finance, 56, 589-616.

Grinblatt, Mark, and Matti Keloharju, 2009, Sensation Seeking, Overconfidence, and Trading Activity, Journal of Finance, 64, 549-578.

Harris, Jeffrey H., and Paul H. Schultz, 1998, The Trading Profits of SOES Bandits, Journal of Financial Economics, 50, 39-62.

Hong, Harrison, and Marcin Kacperczyk, 2009, The Price of Sin: The Effects of Social Norms on Markets, Journal of Financial Economics, 93, 15-36.

Kumar, Alok, 2009, Who Gambles in the Stock Market, Journal of Finance, 64, 18891933.

Linnainmaa, Juhani T., 2003, The Anatomy of Day Traders. AFA 2004 San Diego Meetings. Available at SSRN: http://ssrn.com/abstract=472182 or doi: $10.2139 /$ ssrn. 472182

Linnainmaa, Juhani T., 2005, The Individual Day Trader, 2005, UCLA working paper.

Linnainmaa, Juhani T., 2010, Why Do (Some) Households Trade So Much? AFA 2008 New Orleans Meetings Paper. Available at SSRN: http://ssrn.com/abstract $=972807$

Mahani and Bernhardt, 2007, Financial Speculators' Underperformance: Learning, SelfSelection, and Endogenous Liquidity, Journal of Finance, 62, 1313-1340.

Nicolosi, Gina, Peng, Liang, and Ning Zhu, 2009, Do Individual Investors Learn from Their Trading Experience?, Journal of Financial Markets, 12, 317-336.

Odean, Terrance, 1998, Volume, Volatility, Price, and Profit When All Traders Are above Average, Journal of Finance, 53, 1887-1934.

Odean, Terrance, 1999, Do Investors Trade too Much?, American Economic Review, 89, 1279-1298.

Seasholes, Mark and Guojun Wu, 2007, Predictable Behavior, Profits, and Attention, Journal of Empirical Finance, 14, 590-610.

Seru, Amit, Shumway, Tyler, and Noah Stoffman, 2010, Learning by Trading, Review of Financial Studies, 23, 705-739.

Statman, Meir, 2004, What Do Investors Want?, Journal of Portfolio Management, 153161. 


\section{APPENDIX: Details of Return and Profit Calculations}

We calculate the intraday return from day trading on day $t$ for a particular group (g) of investors weighted by the value of investors' trades:

$$
r_{g t}=\frac{\sum_{i} \sum_{j}\left(S_{i j t}^{L}-B_{i j t}^{L}\right)+\left(S_{i j t}^{S}-B_{i j t}^{S}\right)}{\sum_{i} \sum_{j}\left(B_{i j t}^{L}+S_{i j t}^{S}\right)},
$$

where $B$ and $S$ denote the value of buys and sells (with superscripts $\mathrm{L}$ and $\mathrm{S}$ for long and short transactions, respectively) on day $t$ in stock $i$ by investor $j$. For long positions, the

sales value $\left(S_{i j t}^{L}\right)$ is the value based on the actual transaction price or the closing price if the long position is not closed out prior to the end of trading. For short positions, the purchase value $\left(B_{i j t}^{S}\right)$ is the value based on the actual transaction price or the closing price if the short position is not closed out prior to the end of trading. The numerator in equation $\mathrm{A} 1$ is the intraday gross profit of trader $i$ on day $t$.

Consider a concrete example where an investor buys a stock for $\$ 100$ and sells later in the day for $\$ 102$. On the same day, the investor shorts a stock (the same stock or a different stock) for $\$ 100$ and later covers the short with a purchase at $\$ 97$. The investor makes profits of $\$ 5=(102-100)+(100-97)$. We scale the dollar profits by the total value of the opening positions, $\$ 200=\$ 100+\$ 100$. Thus, we assume the investor put $\$ 200$ of capital at risk and earned an intraday return of $\$ 5 / \$ 200=2.5 \%$. This is an accurate representation of the returns if the investor trades in parallel (i.e., both positions are open at the same time). For investors who trade sequentially, we correctly calculate dollar profits of $\$ 5$, but the capital at risk would be $\$ 100$ rather than $\$ 200$ as the $\$ 100$ would be deployed sequentially. Thus, we always estimate the correct sign of returns, but for day traders who trade sequentially our return estimates are biased toward zero. In addition, we do not know the extent to which traders use leverage, which would increase the magnitude of returns for both gains and losses, but again the sign of the gains and losses would be the same as those in our calculations. In summary, the sign of the day trading returns that we calculate is accurate, though the magnitudes may differ because of sequential trading or the use of leverage. 
When we calculate net returns and net profits, we deduct a 5 bps commission for all trades (10 bps round-trip commission) and a $30 \mathrm{bps}$ transaction tax for sales. Put differently, buys cost 5 bps $\left(C_{b}\right)$ and sells cost 35 bps $\left(C_{s}\right)$. We also increase the capital requirements to reflect the total cost of the opening positions:

$$
r_{g t}^{n e t}=\frac{\sum_{i} \sum_{j}\left(S_{i j t}^{L}-B_{i j t}^{L}\right)+\left(S_{i j t}^{S}-B_{i j t}^{S}\right)-c_{b} *\left(B_{i j t}^{L}+B_{i j t}^{S}\right)-c_{s}\left(S_{i j t}^{L}+S_{i j t}^{S}\right)}{\sum_{i} \sum_{j}\left(B_{i j t}^{L}+S_{i j t}^{S}\right)+c_{b} B_{i j t}^{L}+c_{s} S_{i j t}^{S}},
$$

Continuing our example from above, the net return for the trader would be:

$$
\frac{(102-100)+(100-97)-0.0005(100+97)-0.0035(102+100)}{(100+100)+0.0005 * 100+0.0035 * 100}=\frac{4.19}{200.40}=2.09 \%
$$

Note the net return $(2.09 \%)$ is roughly 40 bps (the total round-trip trading costs of $10 \mathrm{bps}$ in commissions and 30 bps in transaction tax) less than the gross return (2.50\%). The shortfall is slightly greater than $40 \mathrm{bps}$ because we also increase the capital required to open the positions. The numerator in equation A2 is the intraday net profit of trader $i$ on day $t$. 


\section{Table 1: Gross and Net Abnormal Returns from Day Trading: 1992 to 2006}

This table presents the daily percentage alpha from aggregate day trading of day traders. Day trading is defined as round-trip trades by the same stock/investor/day. Each day an investor's trades are included in this analysis if the trader made at least one day trade in the calendar month. The alphas are estimated using the following regression of daily returns: $\left(R_{p t}-R_{f t}\right)=\alpha_{p}+\beta_{p}\left(R_{m t}-R_{f t}\right)+\varepsilon_{p t}$, where $R_{p t}, R_{m t}$, and $\mathrm{R}_{\mathrm{ft}}$ are the portfolio return, market return, and risk-free return (respectively). The gross day trading return is calculated from daily round-trip trades plus the intraday returns on open trades; an open trade is a trade made during the day that results in an outstanding position at the close of the day. The net day trading return assumes a $10 \mathrm{bps}$ round-trip commission and a $30 \mathrm{bps}$ transaction tax on sales. The last column presents the percentage of all trades that are round-trip day trades.

\begin{tabular}{|c|c|c|c|c|c|c|}
\hline \multirow[b]{3}{*}{ All Years } & \multicolumn{2}{|c|}{ Gross } & \multicolumn{2}{|c|}{ Net } & \multirow[b]{2}{*}{ Beta } & \multirow[b]{2}{*}{$\mathrm{R}-\mathrm{Sq}$} \\
\hline & $\alpha(\%)$ & t-stat & $\alpha(\%)$ & t-stat & & \\
\hline & -0.070 & -10.20 & -0.239 & -34.78 & 0.26 & $43 \%$ \\
\hline 1992 & 0.018 & 0.57 & -0.091 & -2.91 & 0.37 & $49 \%$ \\
\hline 1993 & -0.089 & -3.40 & -0.206 & -7.80 & 0.33 & $59 \%$ \\
\hline 1994 & -0.119 & -5.03 & -0.275 & -11.65 & 0.32 & $58 \%$ \\
\hline 1995 & -0.047 & -2.18 & -0.221 & -10.23 & 0.24 & $45 \%$ \\
\hline 1996 & -0.088 & -4.90 & -0.245 & -13.58 & 0.26 & $48 \%$ \\
\hline 1997 & -0.089 & -3.27 & -0.271 & -10.00 & 0.26 & $39 \%$ \\
\hline 1998 & -0.067 & -3.13 & -0.256 & -11.99 & 0.21 & $43 \%$ \\
\hline 1999 & -0.053 & -1.91 & -0.224 & -8.04 & 0.25 & $42 \%$ \\
\hline 2000 & -0.007 & -0.18 & -0.190 & -5.23 & 0.23 & $36 \%$ \\
\hline 2001 & -0.088 & -2.43 & -0.279 & -7.68 & 0.24 & $37 \%$ \\
\hline 2002 & -0.104 & -3.47 & -0.289 & -9.67 & 0.23 & $39 \%$ \\
\hline 2003 & -0.100 & -4.39 & -0.280 & -12.34 & 0.22 & $38 \%$ \\
\hline 2004 & -0.062 & -2.51 & -0.244 & -9.90 & 0.22 & $39 \%$ \\
\hline 2005 & -0.087 & -5.00 & -0.280 & -16.23 & 0.28 & $41 \%$ \\
\hline 2006 & -0.089 & -4.07 & -0.277 & -12.82 & 0.26 & $38 \%$ \\
\hline
\end{tabular}




\section{Table 2: Changes in Day Trading Conditional on Experience and Past Profitability (1993-2005)}

Day trading is defined as round-trip trades by the same stock/investor/day. In panel A, we present percentage of traders who day trade in month $\mathrm{t}-1$ but not in month $\mathrm{t}$. In Panel $\mathrm{B}$, we present percentage of traders who day trade in month $\mathrm{t}-1$ but not in months $\mathrm{t}$ through $\mathrm{t}+11$ We sort traders on experience (rows) and profitability (columns). Experience is the number of previous days on which a trader has day traded through month $\mathrm{t}-1$. Only traders with 10 or more days of day trading experience are included. Profitable day traders are those with mean daily intra-day returns that are positive through month $\mathrm{t}-1$. The analyses begin in 1993 and exclude traders who day traded in $1992 . \mathrm{N}$ is the number of trader/month observations.

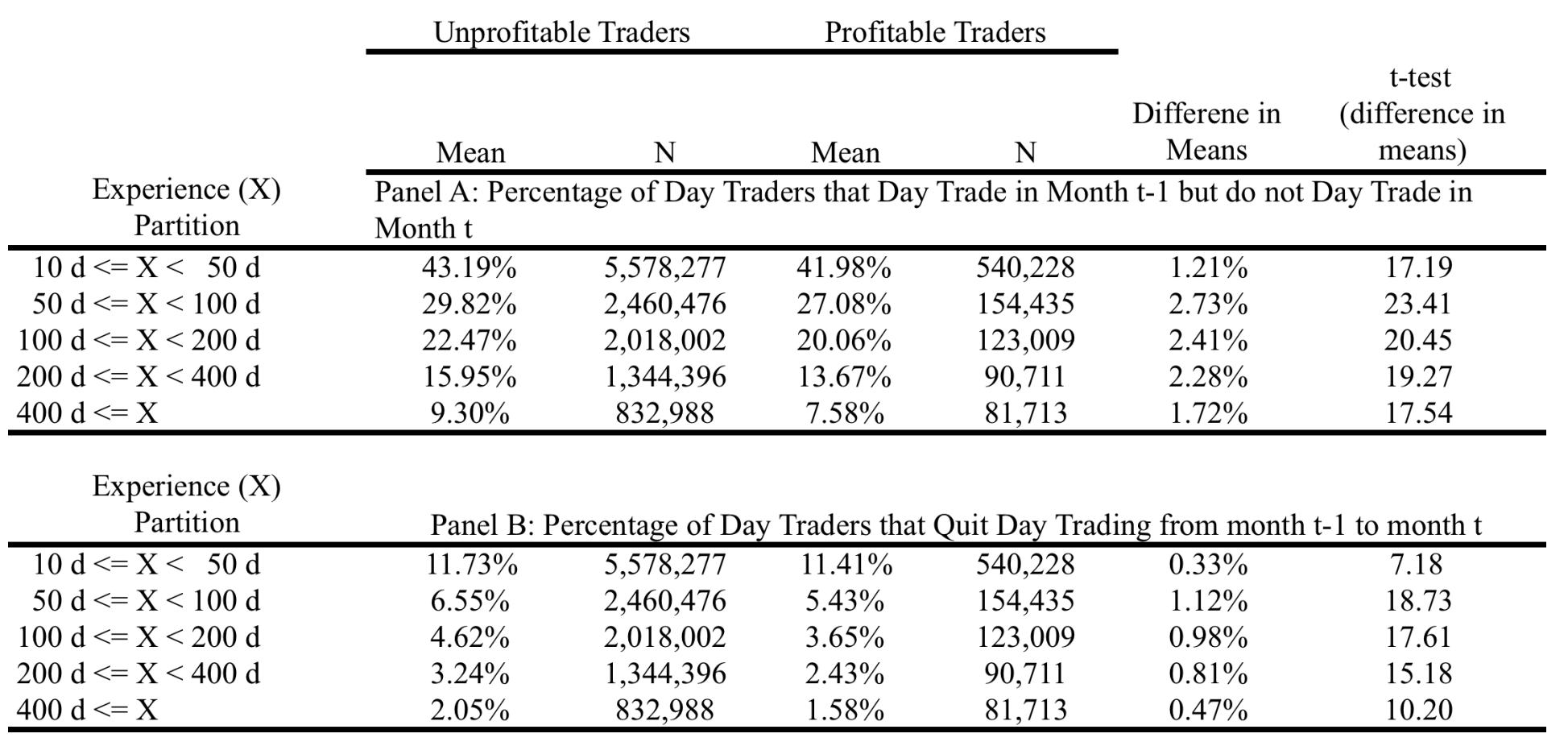




\section{Table 3: Performance of Day Traders based on Prior Year's Day-Trading Experience and Profitability (1993-2006)}

Day Traders are grouped based upon how many days they engaged in day trading and whether their intraday returns were profitbale during the previous 365 days. The alphas are estimated using the following regression of intraday daily returns: $(\mathrm{Rpt}-\mathrm{Rft})=\alpha \mathrm{p}+$ $\beta p(R m t-R f t)+\varepsilon p t$, where Rpt, Rmt, and Rft are the portfolio return, market return, and riskfree return (respectively). The gross day trading return is calculated from daily round-trip trades plus the intraday returns on open trades; an open trade is a trade made during the day that results in an outstanding position at the close of the day. The net day trading return assumes a 10 bps round-trip commission and a 30 bps transaction tax on sales. "Day Trade / All Trade" is the fraction of the group's trading that is round-trip day trades. The last two columns present the share of total market day trading and all trading accounted for by each group.

\begin{tabular}{|c|c|c|c|c|c|c|c|c|c|}
\hline \multirow{3}{*}{$\begin{array}{c}\text { \# Days of Day } \\
\text { Trading Experience } \\
\text { in Previous Year }\end{array}$} & \multicolumn{2}{|c|}{ Gross } & \multicolumn{2}{|c|}{ Net } & \multirow[b]{2}{*}{ Beta } & \multirow[b]{2}{*}{$\mathrm{R}-\mathrm{Sq}$} & \multirow[b]{2}{*}{$\begin{array}{l}\text { Average } \\
\text { Daily N }\end{array}$} & \multirow[b]{2}{*}{$\begin{array}{l}\text { Day Trades / } \\
\text { All Trades }\end{array}$} & \multirow[b]{2}{*}{$\begin{array}{l}\text { Share of All } \\
\text { Day Trading } \\
\text { by Volume }\end{array}$} \\
\hline & $\alpha(\%)$ & t-stat & $\alpha(\%)$ & t-stat & & & & & \\
\hline & \multicolumn{9}{|c|}{ Profitable Day Traders } \\
\hline $0 \mathrm{~d}<=X<5 \mathrm{~d}$ & -0.066 & -7.64 & -0.140 & -16.26 & 0.33 & $46 \%$ & 14936 & $9.73 \%$ & $7.81 \%$ \\
\hline $6 \mathrm{~d}<=X<10 \mathrm{~d}$ & 0.001 & 0.18 & -0.107 & -14.57 & 0.29 & $46 \%$ & 2110 & $18.90 \%$ & $2.12 \%$ \\
\hline $11 \mathrm{~d}<=\mathrm{X}<20 \mathrm{~d}$ & 0.053 & 7.75 & -0.070 & -10.32 & 0.27 & $47 \%$ & 1976 & $22.53 \%$ & $2.50 \%$ \\
\hline $21 \mathrm{~d}<=X<40 \mathrm{~d}$ & 0.120 & 19.33 & -0.019 & -3.14 & 0.24 & $47 \%$ & 1732 & $26.34 \%$ & $2.90 \%$ \\
\hline $41 \mathrm{~d}<=X<80 \mathrm{~d}$ & 0.197 & 35.39 & 0.035 & 6.34 & 0.21 & $46 \%$ & 1455 & $33.36 \%$ & $3.20 \%$ \\
\hline \multirow[t]{2}{*}{$80 \mathrm{~d}<=\mathrm{X}$} & 0.333 & 72.65 & 0.118 & 26.03 & 0.17 & $45 \%$ & 1724 & $50.52 \%$ & $6.61 \%$ \\
\hline & \multicolumn{9}{|c|}{ Unprofitable Day Traders } \\
\hline $0 \mathrm{~d}<=X<5 \mathrm{~d}$ & -0.139 & -16.10 & -0.213 & -24.60 & 0.33 & $46 \%$ & 46078 & $8.95 \%$ & $20.55 \%$ \\
\hline $6 \mathrm{~d}<=\mathrm{X}<10 \mathrm{~d}$ & -0.167 & -20.75 & -0.270 & -33.60 & 0.31 & $47 \%$ & 9468 & $18.52 \%$ & $6.81 \%$ \\
\hline $11 \mathrm{~d}<=X<20 \mathrm{~d}$ & -0.171 & -21.98 & -0.289 & -37.26 & 0.31 & $47 \%$ & 10335 & $23.99 \%$ & $8.77 \%$ \\
\hline $21 \mathrm{~d}<=X<40 \mathrm{~d}$ & -0.171 & -23.05 & -0.310 & -41.83 & 0.30 & $48 \%$ & 10308 & $30.47 \%$ & $10.47 \%$ \\
\hline $41 \mathrm{~d}<=X<80 \mathrm{~d}$ & -0.166 & -23.71 & -0.332 & -47.56 & 0.28 & $49 \%$ & 9184 & $37.81 \%$ & $11.34 \%$ \\
\hline $80 \mathrm{~d}<=\mathrm{X}$ & -0.132 & -21.88 & -0.348 & -57.90 & 0.25 & $50 \%$ & 9639 & $50.72 \%$ & $16.91 \%$ \\
\hline
\end{tabular}




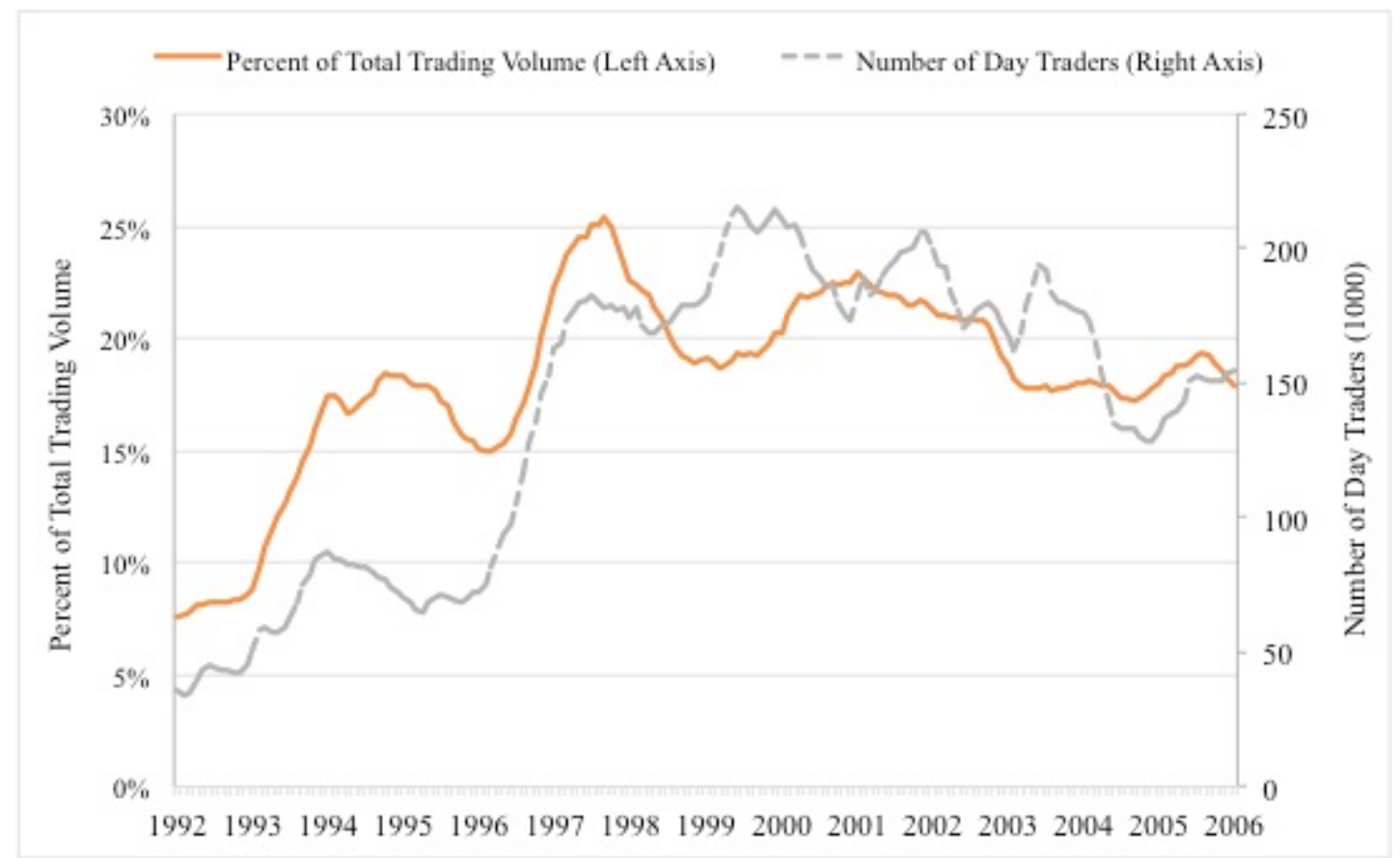

Figure 1: Day Trading as a Percent of Total Volume and Number of Individual Da Traders

The figure presents the 12-month moving average for (1) the number of individ investors who engage in day trading and (2) day trading as a percent of total tradi volume. 


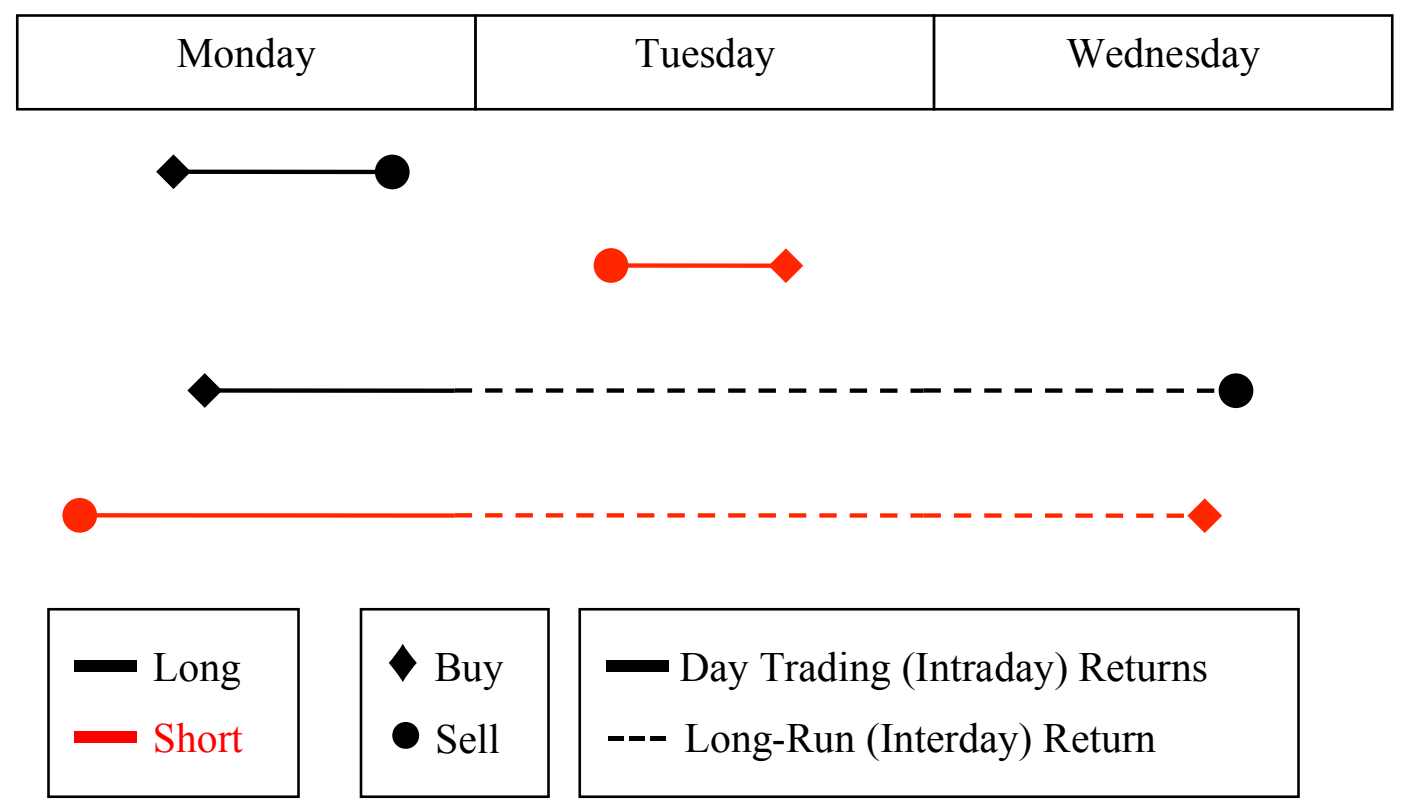

Figure 2: Example of Trading Activity for a Day Trader

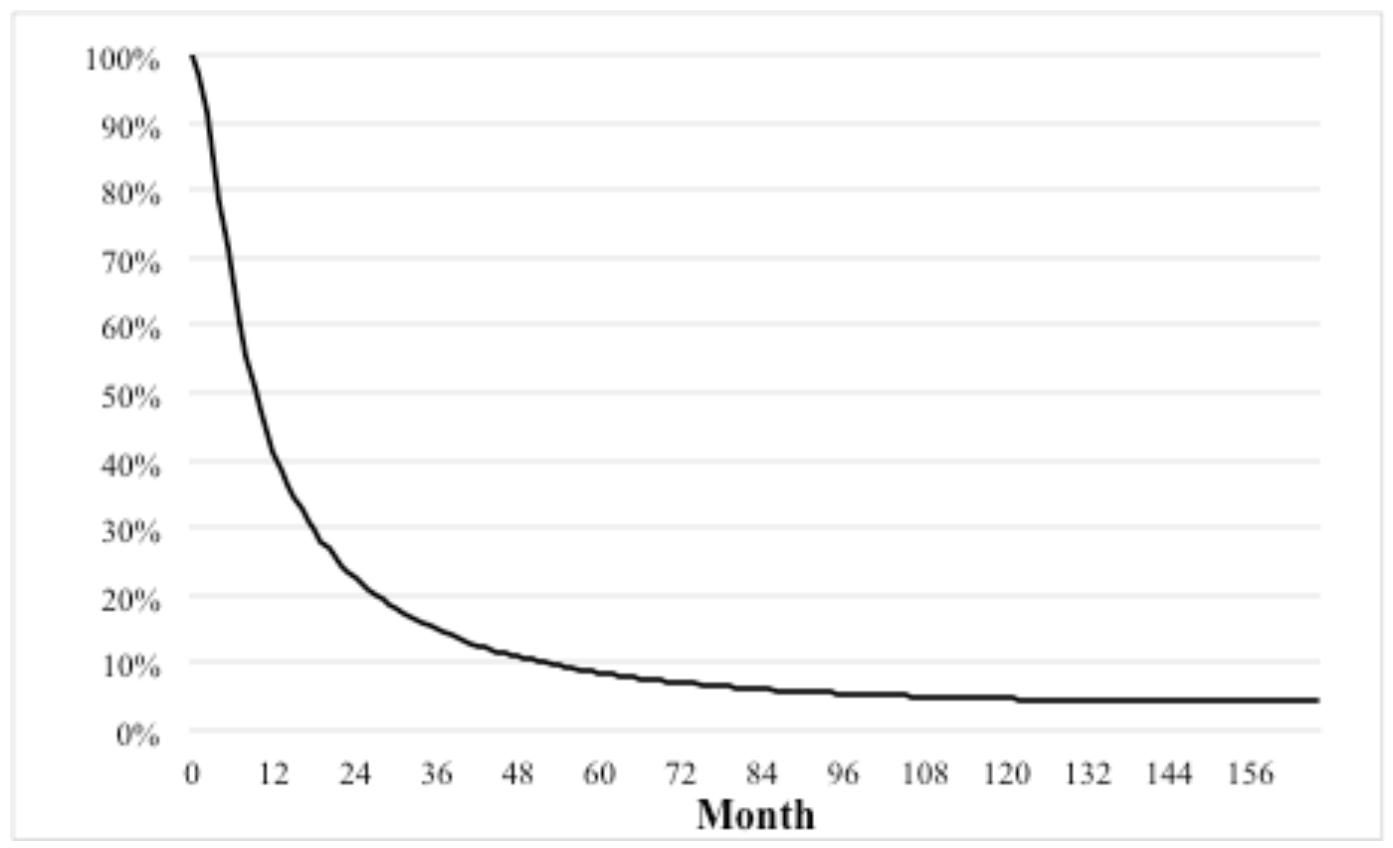

Figure 3: Day Trading Survival Function for Traders with 10 or more Days of Day Trading Experience.

Observations are monthly. Traders are considered to have quit day trading in the first month for which we observe no day trading in twelve consecutive months. The sample consists of day traders with a minimum of 10 days of day trading. The entry month is the first month when they exceed 9 days of day trading. 


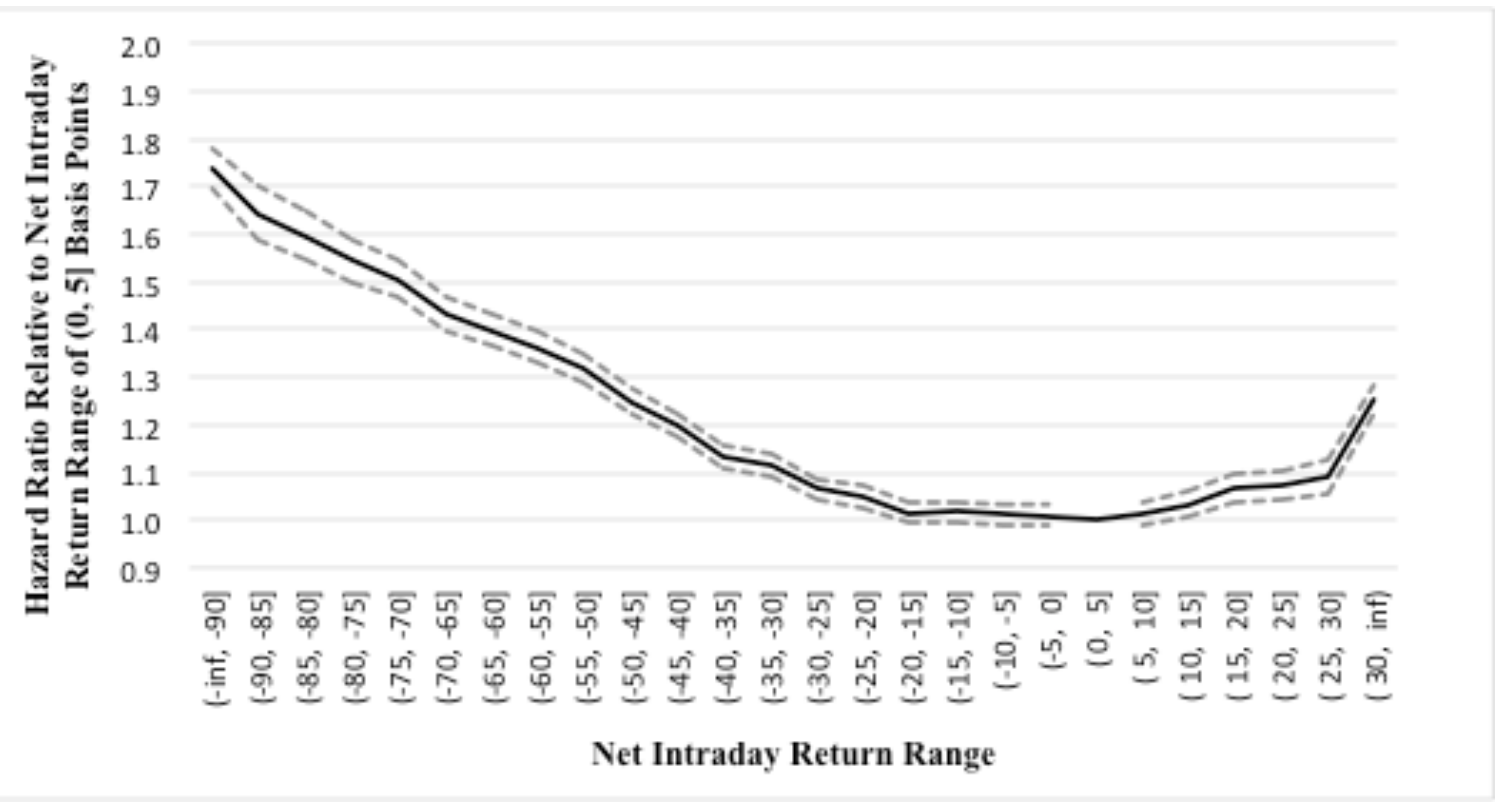

Figure 4: Hazard Ratio for Quitting Day Trading Conditional on Past Returns 1993-2005.

Observations are monthly and exclude traders who day traded in 1992. Traders are considered to have quit day trading in the first month for which we observe no day trading in twelve consecutive months. The figure reports the hazard ratio for quitting and the $95 \%$ confidence interval (dashed lines) for different return categories relative to the default category of $(0,5 \mathrm{bps}]$ where the hazard ratio is equal to one by construction. The sample consists of day traders with a minimum of 10 days of day trading. The entry month is the first month when they exceed 9 days of day trading. Returns are the average net daily intraday returns from the month of the $1^{\text {st }}$ day trade to the end of prior month. 
Figure 5a: Percentage of All Traders

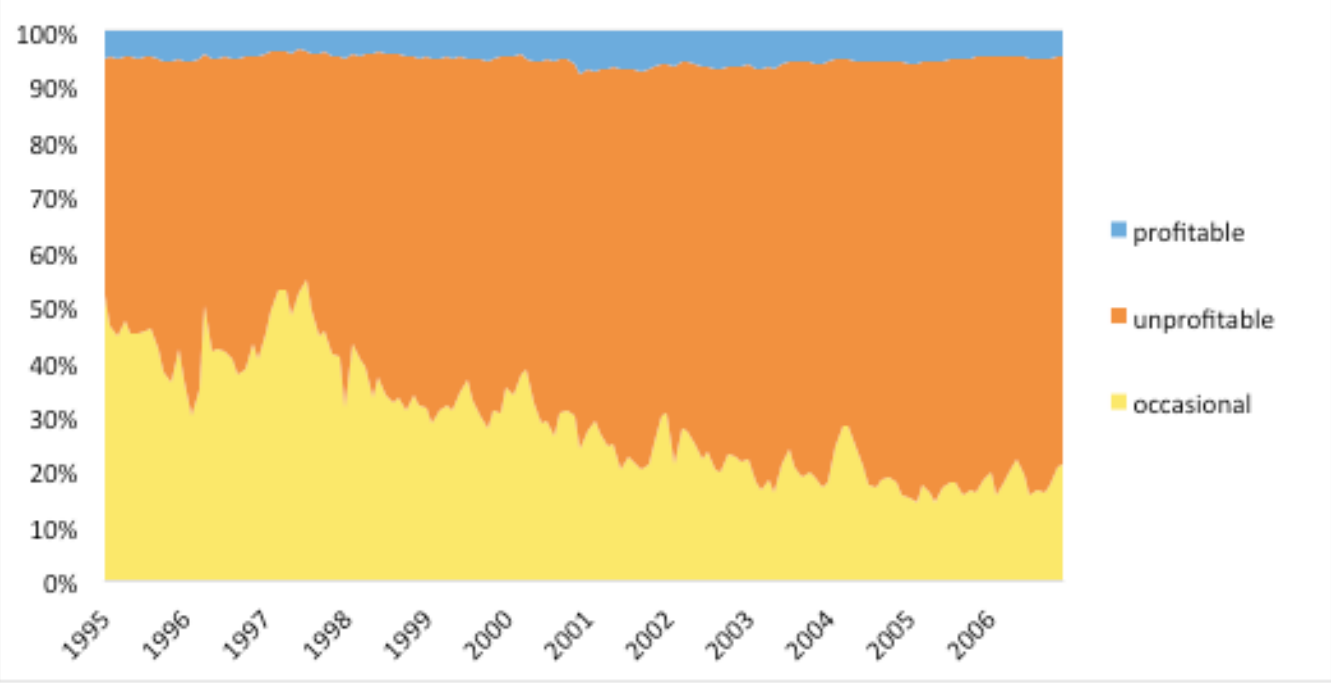

Figure 5b: Percentage of Day Trading Volume

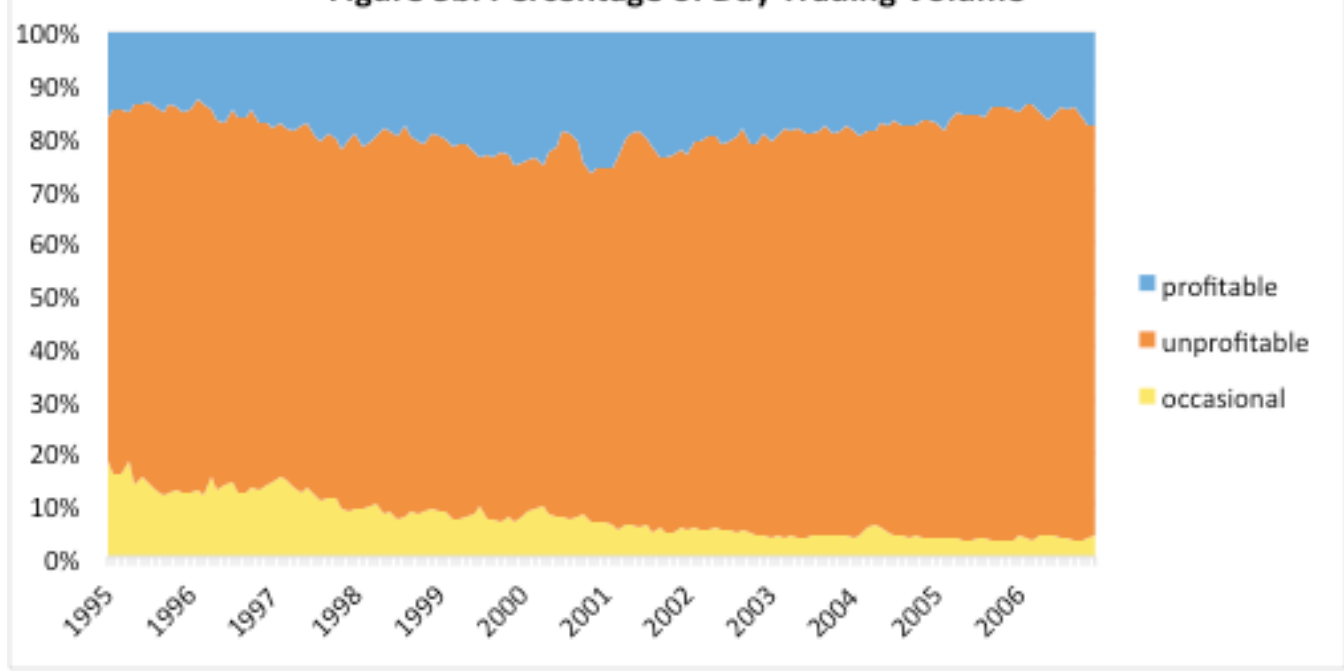

Figure 5: Day Trading by Occasional Traders, First Time Traders, Unprofitable Traders, and Profitable Traders

Occasional day traders are those with 1 to 9 days of past day trading. Profitable (unprofitable) traders are traders with 10 or more days of past day trading whose cumulative intraday net profits are positive (negative or zero). 


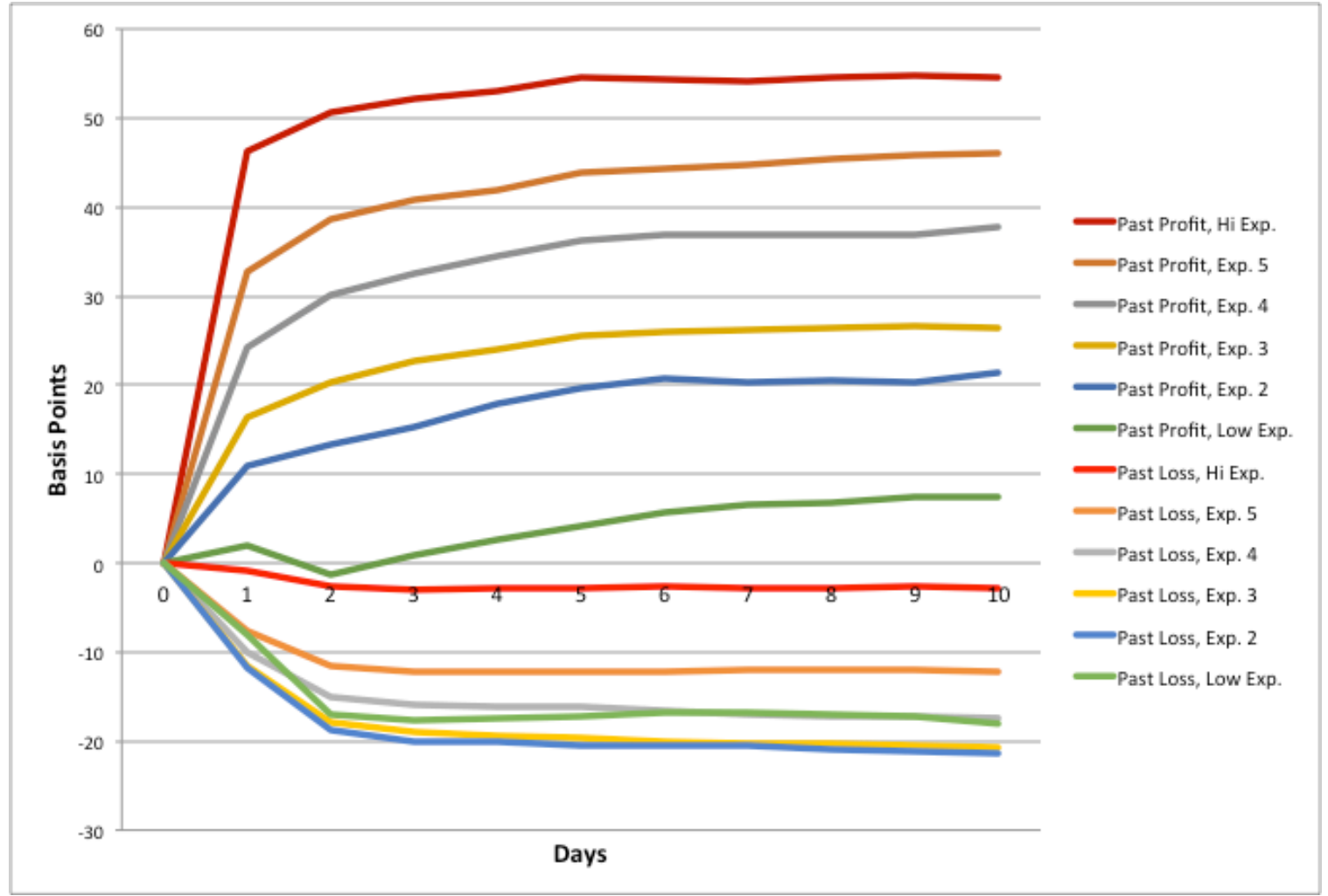

Figure 6: Cumulative (market-adjusted) abnormal returns (CARs) in event time for stocks bought less stocks sold for day traders sorted by trading experience and profitability during the previous year 1993-2005.

On event day 1, traders who day trade that day are sorted based on net profitability of intraday trades and day trading experience over previous year. Profitable (unprofitable) traders are those with cumulative intraday net profits over the previous 365 calendar days that are positive (negative or zero). Experience bins are based on number of days of day trading during the previous 365 days with: Low experience (0-5), Exp. 2 (6-10), Exp 3 (11-20), Exp 4 (21-40), Exp 5 (41-80), Hi Exp ( > 80). 